\title{
Safety Design and Development of a Human-Robot Collaboration Assembly Process in the Automotive Industry
}

\author{
Sahar Heydaryan ${ }^{1, * \mathbb{C}}$, Joel Suaza Bedolla ${ }^{2}$ and Giovanni Belingardi ${ }^{1}$ \\ 1 Department of Mechanical and Aerospace Engineering (DIMEAS), Politecnico di Torino, 10129 Torino, Italy; \\ giovanni.belingardi@polito.it \\ 2 Department of Management and Production Engineering (DIGEP), Politecnico di Torino, 10129 Torino, Italy; \\ joel.sauza@polito.it \\ * Correspondence: Sahar.Heydaryan@polito.it; Tel.: +39-324-95-06-120
}

Received: 20 December 2017; Accepted: 17 February 2018; Published: 28 February 2018

\begin{abstract}
Human-robot collaboration (HRC) is a complex procedure in manufacturing due to the problems posed by compatibility and operational safety among humans and robots, and by task definitions among them in a collaborative order. In this paper, the research results of the human-robot collaboration study for the case of an automotive brake disc assembly is presented. The analytic hierarchy process (AHP) is proposed as a decision-making method for the human-robot collaboration system, and detailed hierarchical task analysis (HTA) is applied to allocate operational tasks to humans and robots, thus reducing the chance of duty interference. Additionally, a virtual environment software (Tecnomatix Process Simulate, version 11.1,80, Siemens, Munich, BY, Germany, 2012) is used to model the assembly workstation, providing an opportunity to evaluate the feasibility of the process through different scenarios. Finally, an experimental test is conducted to evaluate the performance of the assembly procedure. This research proves that, although human-robot collaboration increases the total process time slightly, this collaboration improves human ergonomics considerably and reduces the operator injury risk.
\end{abstract}

Keywords: HRC; HTA; virtual environment; ergonomic; safety; brake disc assembly

\section{Introduction}

Today there is strong competition among industries toward factory-wide automation; manufacturers apply automation in their production line since they have a high interest in increasing the production rate without jeopardizing the quality and accuracy of the final product. Recently, robots have played major roles in automated production lines due to their superior capabilities. Although robots have been widely used to perform repetitive, non-critical tasks, such as handling, welding, and joining [1], recently researchers have developed specific studies with the aim of integrating them in a collaborative workspace. A collaborative workspace deals with the cooperation of humans and robots trying to accomplish a specific task. However, using collaborative robots, operator safety should not be put at risk in any aspect; this requires clear task definition and allocation for humans and robots in a collaborative work cell [2].

A safety design framework for human-robot collaboration in the absence of predefined regulations has been proposed by Reference [3]; authors have tried various strategies to design a safe workspace. Their suggested strategies have used different devices, such as safety fences, sources, light curtains, cameras, and robot speed and area restriction stop systems. The effectiveness of the safety design has been evaluated by risk assessment methods; however, still there is a gap between this strategy and safety regulations. A practical case study of human-robot collaboration has been presented in 
Reference [4]; using inverse kinematic theories, authors have made a control framework to define the robot trajectory completely for the case of the automotive homokinetic joint assembly process.

Authors of References [5,6] have focused on the speed and separation method, defined as one of the available ISO standards for collaborative robots, to increase operator safety in the shared workspace. Having used this standard, the safety of the operator in the manufacturing cell increased by determining the minimum protective distance between humans and robots. With respect to previous contributions in the field, the authors of Reference [7] have investigated the advantage of virtual reality technologies to simulate the assembly and maintenance process in a digital environment that allows the simulation of the human and robot interaction. They proved that these technologies appreciably reduce the time and cost of production development. In Reference [8], in aiming to design novel manufacturing systems, the authors considered the safety issues of the operators with the possibility of planning collision-free paths for multiple robots in a Virtual environment. In Reference [9], the needs of modern manufacturing industries that have led to cooperation between humans and industrial robots were discussed. In this study, the system, called Beware of the Robot (BOR), is used to train the operators in human-robot interaction, considering the safety issues for humans and enhancing production. In Reference [10], the authors explained the design method in hybrid reconfigurable system (H-RS) engineering, which maintains the design method and clarifies the concept. This method was utilized to develop a hybrid reconfigurable work cell for assembling a top-class car chassis. During human-robot collaboration, task allocation is one of the most challenging problems. Researchers of Reference [11] have used the task analysis method to define the necessary order in collaboration tasks in an assembly cell. Using this method, they reduced the chance of duty interference between an operator and the assistant robot.

In the present research, the effectiveness of human-robot collaboration for the assembly of a brake disc is proven in a general framework by the analytic hierarchy process (AHP) approach. In the second step, the hierarchical task analysis (HTA) method is used to define and allocate human and robot tasks without their duty interference. In the third step, after human and robot tasks are defined, and the brake disc assembly process is simulated using the virtual environment software. In the last step, after the efficiency of the model is evaluated in a real workspace situation, problems related to the improper position of the robot during the process in the laboratory are solved, and new tasks are added to the HTA diagram to improve the efficiency of the human-robot collaboration.

\section{Manual Assembly Process}

The assembly of a brake disc is completed through a procedure of five sequential steps. (a) In the first step, semi-finished parts, such as the snap ring, upright, and bearing, come from the previous station or from the shelf; (b) In the second step, an operator takes the dust protection plate from the plate box and puts it on the semi-finished parts. Then the operator takes three M6 type screws from the screw box and inserts them into the dust protection plate; (c) In the third step, the operator takes the hub from the hub box and puts it on the dust protection plate, brings the parts to be assembled to the press machine, and puts them in place. At this moment, the press machine inserts the hub inside the previously assembled parts with pressure and then the operator brings back the assembled components to the production cell; (d) In the fourth step, the operator takes the brake disc from the disc box and puts it on the assembled components; (e) In the last step, the operator takes two M8 type screws from the screw kit and inserts them on the assembled parts and tightens them, as shown in Figure 1.

To describe in a more detailed way the working situation of the operator, it is better to clearly define the working conditions, as shown in Figure 2. Every day, each operator should work $8 \mathrm{~h} / \mathrm{shift}$, each brake disc weights $5 \mathrm{~kg}$, and the assembly of one brake disc takes around $3 \mathrm{~min}$; considering the operator's shift hours and the brake disc assembly period, the operator should assemble approximately 160 brake discs and lift $800 \mathrm{~kg}$ throughout each working day. 


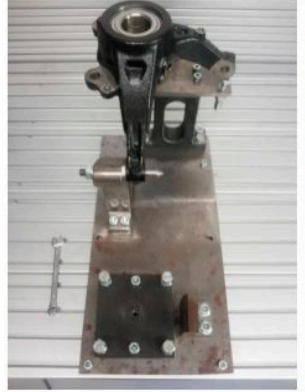

(a) First step

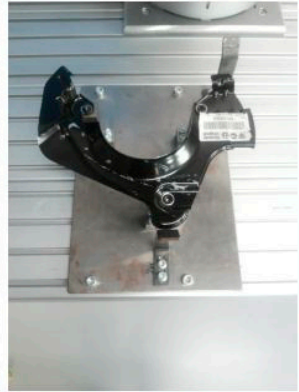

(b) Second step

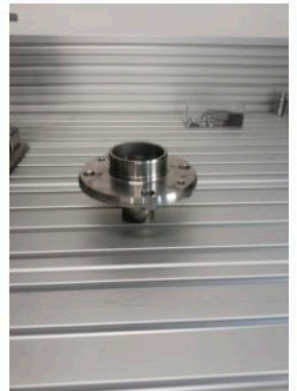

(c) Third step

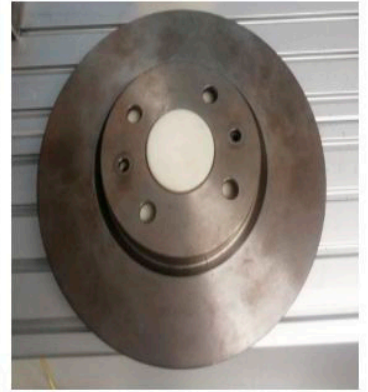

(d) Fourth step

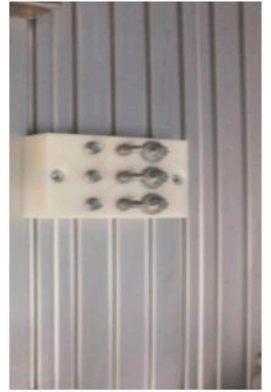

(e) Fifth step

Figure 1. Brake disc elements for assembly operation. (a) First step; (b) Second step; (c) Third step; (d) Fourth step; (e) Fifth step.

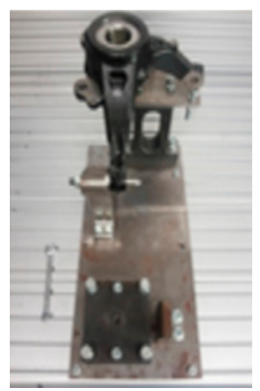

(a) First step

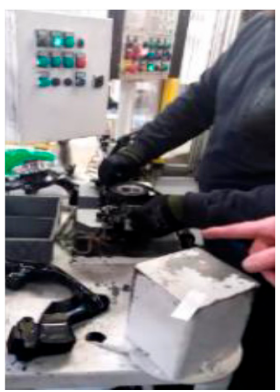

(b) Second step

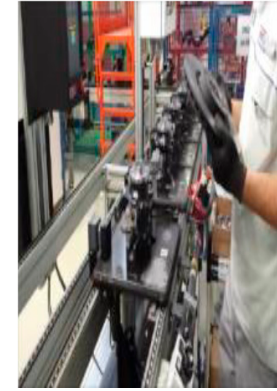

(c) Third step

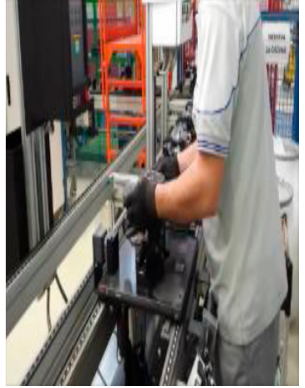

(d) Fourth step

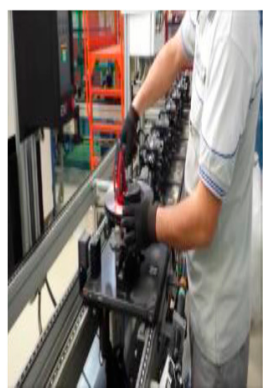

(e) Fifth step

Figure 2. The sequence steps of the manual brake disc assembly on the production line. (a) First step; (b) Second step; (c) Third step; (d) Fourth step; (e) Fifth step.

\section{Quantitative Analysis by the Analytic Hierarchy Process (AHP)}

Evaluating the efficiency of a process qualitatively with respect to various criteria for finding the optimum solution is not an easy task; however, using quantitative analysis, such as the analytic hierarchy process (AHP) [12,13], provides a good solution to satisfy this objective. In the present case study of the assembly of a brake disc, the considered evaluation criteria are productivity, human fatigue, safety, and quality. While the comparative solutions are one that employs a human-only system and one that is based on a human-robot collaboration system, AHP analysis is used as the evaluation methodology. The four criteria of productivity, human fatigue, safety, and quality were considered the most important by both the factory managers and the expert personnel involved in this activity; other criteria were ignored since they would not significantly affect this human-robot collaboration procedure. To implement this activity, three expert personnel participated in decision-making and planning, and they support the author's choice of the AHP method to evaluate the efficiency of the human-robot collaboration.

The AHP analysis proposed by References [14-18] is defined in eight general steps, as follows:

1. Identify the problem and define the goals.

2. Construct the general framework of the AHP analysis in a hierarchically descending order; this means that the objective set at the highest level is followed by the criteria set at the intermediate levels, and then solutions, which are set at the lowest levels.

3. Use the pair-wise comparison scale for AHP preference from References [14-18], ranging from 1-9 (intensity of importance) as shown in Table 1. In this scale, 1 expresses the equally-preferred status and 9 expresses the extremely-preferred status.

4. Construct the pair-wise comparison matrix for the four criteria, as in Tables 2 and 3. 
5. Construct the pair-wise comparison matrices of alternatives for each specific criterion; this means that if there are $n$ criteria and $\mathrm{m}$ alternatives available in the procedure, there should be $\mathrm{n}$ matrices with the size of $\mathrm{m} \times \mathrm{m}$, as in Tables 4-7.

6. Construct the synthesized comparison matrices of alternatives for each specific criterion to calculate the priority vectors; each value of the synthesized matrix is calculated by dividing the same element in Tables 4-7 by the summation of its column. Each priority vector is then calculated as the average of the new matrix row, as shown in Tables 4-7.

7. Calculate the consistency ratio for the pair-wise matrix of the four criteria to check the consistency of the analysis comparisons.

8. Construct the priority matrix of alternatives (solutions), as in Table 8.

The pair-wise comparison matrix of the four criteria, as reported in Tables 2 and 3, aims to show the importance of one criterion over the others [18]. In this research, the intensity and importance of each criteria was chosen through a group decision. This sorted out that (see the columns of Table 2) the safety factor has the highest importance intensity, followed by productivity and quality factors, while the human fatigue factor has the lowest importance intensity. The pair-wise comparison of alternatives with respect to each criterion is evaluated at steps 4 and 5 based on the actual system operation. The use of a human-robot collaboration design can give a greater importance to productivity and quality factors so that they have, comparatively, the same intensity and importance to reach the goal in the assembly of the brake disc (Tables 4 and 5). It can be noted this also reduces the workload burden of the human operator (Table 6) while, due to the close range of human and robot cooperation and consequent increase of the injury risk, there might be a much lower safety level in the human-robot design (Table 7) [11].

Consistency of the analysis comparison is determined by calculating the consistency ratio as in Equation (1):

$$
C R=\frac{C I}{R I}
$$

where $C I$ is consistency index and $R I$ is average random consistency.

$R I$ is a predefined value depending on the size of the pair-wise comparison matrices; in this case, due to the size of the pair-wise comparison matrix for the four criteria, which is $4 \times 4, R I$ is equal to 0.9 [16]. $C I$ is calculated according to Equation (2):

$$
C I=\frac{\lambda_{\max }-n}{n-1}
$$

where $\lambda_{\max }$ is the maximum eigenvalue and $\mathrm{n}$ is the size of the four criteria pair-wise comparison matrix. To calculate $\lambda_{\max }$, the weighted sum matrix of Table 8 is calculated by multiplying each priority vector element into the respective column and adding the values. Then, each element of the weighted sum matrix is divided by the respective priority vector element and the average values are reported as $\lambda_{\max }$. A consistency ratio lower than 0.1 proves the suitability of the pair-wise comparison matrix. More information related to the estimation of the consistency ratio is reported in Reference [14].

Table 1. Average random consistency (RI).

\begin{tabular}{cccccccccc}
\hline Size of Matrix & $\mathbf{1}$ & $\mathbf{2}$ & $\mathbf{3}$ & $\mathbf{4}$ & $\mathbf{5}$ & $\mathbf{6}$ & $\mathbf{7}$ & $\mathbf{8}$ & $\mathbf{9}$ \\
\hline Random consistency & 0 & 0 & 0.58 & 0.9 & 1.12 & 1.24 & 1.32 & 1.45 & 1.49 \\
\hline
\end{tabular}

The last step is to construct the priority matrix of alternatives and to calculate the overall priority vectors. The overall priority vector of each solution is calculated as summation of the priority vector of each alternative multiplication (in this case there are four priority vectors, related to the four criteria of safety, productivity, quality, and human fatigue for each alternative) to the respective priority vectors listed in Table 8. The alternative with the highest overall priority value provides the result of the 
analysis. Following the AHP procedure described above, the hierarchy of the problem is developed as shown in Figure 3.

The priority of each decision alternative with respect to its contribution to different criteria is decided by project managers and is presented in Table 2. By determining the pair-wise comparison matrix for each criteria, it is possible to complete the calculation using manual estimation or expert choice as an AHP in the developer software.

Table 2. Pair-wise comparison matrix for four criteria.

\begin{tabular}{ccccc}
\hline Human-Robot Collaboration & Productivity & Quality & Human Fatigue & Safety \\
\hline Productivity & 1 & 1 & 2 & $1 / 2$ \\
Quality & 1 & 1 & 2 & $1 / 2$ \\
Human Fatigue & $\frac{1}{2}$ & $1 / 2$ & 1 & $1 / 6$ \\
Safety & 2 & 2 & 6 & 1 \\
\hline
\end{tabular}

After developing Table 2, the pair-wise comparison matrix is synthesized by dividing the matrix of each element by its column total. For instance, the value 0.222 in Table 3 is calculated by dividing 1 (from Table 2) by 4.5 , which is the sum of all the column terms shown in Table $2(1+1+1 / 2+2)$.

The priority vector of the synthesized matrix is calculated by dividing the row averages, as shown in Table 3. For instance, the productivity priority based on human-robot collaboration criterion, as shown in Table 3, is estimated by dividing the sum of the rows $(0.222,0.222,0.1818$, and 0.230$)$ by the number of columns (4).

The priority vector for human-robot collaboration, shown in Table 3, is given below:

$$
\left[\begin{array}{l}
0.214 \\
0.214 \\
0.097 \\
0.476
\end{array}\right]
$$

Table 3. Synthesized matrix for human-robot collaboration.

\begin{tabular}{cccccc}
\hline Human-Robot Collaboration & Productivity & Quality & Human Fatigue & Safety & Priorities \\
\hline Productivity & 0.222 & 0.222 & 0.1818 & 0.230 & 0.214 \\
Quality & 0.222 & 0.222 & 0.1818 & 0.230 & 0.214 \\
Human Fatigue & 0.111 & 0.111 & 0.9090 & 0.0768 & 0.097 \\
Safety & 0.444 & 0.444 & 0.5454 & 0.460 & 0.476 \\
\hline & $\lambda_{\max }=4.0197, C I=0.00656, R I=0.9, C R=0.00729<0.1$. \\
$0.214\left[\begin{array}{c}1 \\
1 \\
1 / 2 \\
2\end{array}\right]+0.214\left[\begin{array}{c}1 \\
1 \\
1 / 2 \\
2\end{array}\right]+0.097\left[\begin{array}{l}2 \\
2 \\
1 \\
6\end{array}\right]+0.476\left[\begin{array}{c}1 / 2 \\
1 / 2 \\
1 / 6 \\
1\end{array}\right]=\left[\begin{array}{c}0.860 \\
0.860 \\
0.390 \\
1.914\end{array}\right]$
\end{tabular}

By dividing all the weighted sum matrix elements, obtained from Equation (4), by their respective priority vector elements as below:

$$
\begin{aligned}
& 0.860 / 0.214=4.0186 \\
& 0.860 / 0.214=4.0186 \\
& 0.390 / 0.097=4.0206 \\
& 1.914 / 0.476=4.0210
\end{aligned}
$$


The $\lambda_{\max }$ can be calculated as the average of the above values:

$$
\lambda_{\max }=(4.0186+4.0186+4.0206+4.0210) \div 4=16.0788 / 4=4.0197
$$

It is now possible to calculate the consistency index, CI:

$$
C I=\lambda_{\max }-n / n-1=4.0197-4 / 4-1=0.00656
$$

Based on References [14-19], as presented in Table 1, for a matrix with the size of 4, the random consistency ratio, $R I$, is 0.9 and the consistency ratio, $C R$, is calculated as follows:

$$
C R=C I / R I=0.00656 / 0.9=0.00729
$$

Due to the fact that $C R$ is less than 0.1 , the judgments are acceptable. Similarly, all the pair-wise comparison matrices along with the priority vectors for different criteria are calculated, as presented in Tables 4-7.

Table 4. Pair-wise comparison matrix for productivity.

\begin{tabular}{cccc}
\hline Productivity & Human & Human-Robot & Priority Vector \\
\hline Human & 1 & $1 / 7$ & $0.25 / 2=0.125$ \\
Human-Robot & 7 & 1 & $1.75 / 2=0.875$ \\
\hline
\end{tabular}

Table 5. Pair-wise comparison matrix for quality.

\begin{tabular}{cccc}
\hline Quality & Human & Human-Robot & Priority Vector \\
\hline Human & 1 & $1 / 7$ & $0.25 / 2=0.125$ \\
Human-Robot & 7 & 1 & $1.75 / 2=0.875$ \\
\hline
\end{tabular}

Table 6. Pair-wise comparison matrix for human fatigue.

\begin{tabular}{cccc}
\hline Human Fatigue & Human & Human-Robot & Priority Vector \\
\hline Human & 1 & $1 / 6$ & $0.285 / 2=0.1425$ \\
Human-Robot & 6 & 1 & $1.714 / 2=0.857$ \\
\hline
\end{tabular}

Table 7. Pair-wise comparison matrix for safety.

\begin{tabular}{cccc}
\hline Human Fatigue & Human & Human-Robot & Priority Vector \\
\hline Human & 1 & $1 / 6$ & $0.285 / 2=0.1425$ \\
Human-Robot & 6 & 1 & $1.714 / 2=0.857$ \\
\hline
\end{tabular}

Table 8. Priority matrix of alternatives.

\begin{tabular}{ccccc}
\hline Overall Priority Vector & Productivity & Quality & Human Fatigue & Safety \\
\hline Human & 0.02675 & 0.02675 & 0.0138 & 0.3965 \\
Human-Robot & 0.1872 & 0.1872 & 0.0831 & 0.0790 \\
\hline
\end{tabular}

The overall priorities of the human system and the human-robot system can be evaluated according to:

Overall priority of the human system $=0.02675+0.02675+0.01380+0.39650=0.4638$

Overall priority of the human-robot system $=0.1872+0.1872+0.0831+0.0790=0.5365$

Their values are 0.4638 and 0.5365 , and this confirms that the human-robot system is the preferred solution which can satisfy the criteria. 


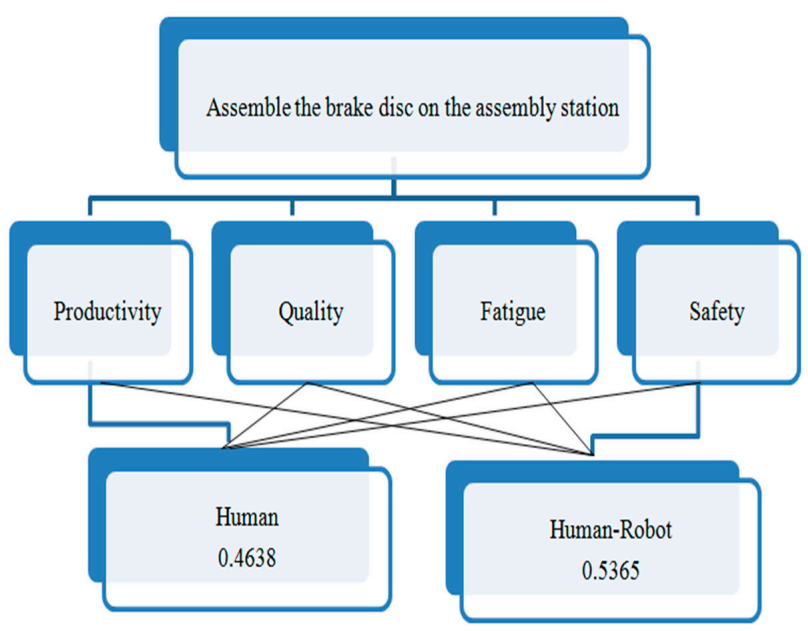

Figure 3. The analytic hierarchy process (AHP) model of tasks.

\section{General Framework of Human-Robot Collaboration Procedure}

The assembly of a brake disc is performed in several steps in an actual production environment. In the laboratory environment, it is supposed that the human-robot collaboration can be concentrated into one cell. This experimental cell is composed of two different zones: picking and assembly areas. The picking area is the zone where the components to be used in the assembly process are located; the robot should be able access to them. In the assembly area, the semi-finished parts are located and the assembly process has to be performed by the operator and robot. The components are located on the workbench, including the screw kit, brake disc, dust protection plate, tip kit, and semi-finished parts; the robot manipulator picks them in an ordered sequence as shown in Figure 4.

In order to investigate the feasibility of this activity, a robot manipulator with seven degrees of freedom has was introduced to support and help the operator to complete the assembly activity. The main purpose of applying a robot in the assembly process is to improve operator ergonomics and increase productivity. As mentioned before, tasks are generally subdivided into three main categories: picking, placing of assembly parts, and tightening of screws. These tasks will be allocated to the operator or to the robot based on the sensitivity of tasks and the ability of humans and robots to perform those tasks.

To accomplish these arrangements, sequences and proper tasks allocation are quite critical and require a complicated process. If the assignment of tasks does not take place properly, then the operator will probably face serious ergonomic problems, such as muscular and back pain, due to performing repetitive tasks and heavy workloads. Due to these facts, the robot manipulator was introduced to reduce the workload and improve the ergonomics of the operator. The location of the robot manipulator during this collaborative activity is very important with respect to the operating tasks and feasibility of the assembly.

In order to respect safety regulations, and based on ISO 10218-2 norm 5.10.2 [19], an emergency stop button is located at end of the workbench which is connected to the robot with cables and controlled by software to stop the robot motions. In this activity, the safety-rated monitored stop (SMS) was used to fulfill the safety regulations. The robot has no motion whenever the operator is inside the collaboration space. Whenever the operator wants to enter the collaboration area, he should press the button to command the robot to stop its movements until he performs his tasks. After the operator finishes his duties, he should again press the button, which means he wants to exit the collaborative zone. Moreover, after the operator completely exits, the robot manipulator can continue its jobs and complete the tasks.

In order to achieve effective collaboration between humans and robots, it is necessary to plan suitable arrangements and define clear duties considering capability and reliability, both for the human 
and the robot. In the advanced reproduced experimental tests in laboratory environments, proper sensors, such as safety mats, laser scanners, or other detective devices, can be used. These detective devices are able to recognize and detect any objects in the surrounding environment and, by proper elaboration of this kind of information, prevent possible collisions. The mentioned solution based on a stop button at the end of the workbench was implemented in a preliminary practical test based on the manual assembly operation. The collaboration activity was repeated five times and took two working weeks to accomplish.

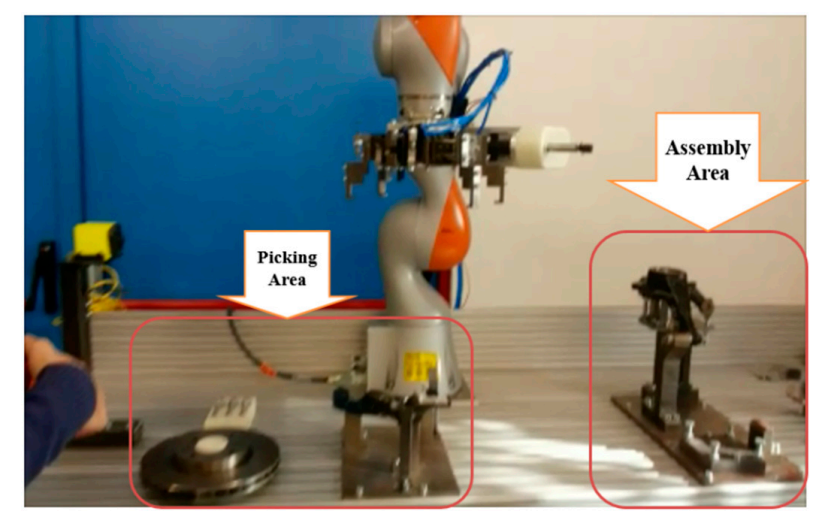

Figure 4. Workbench area.

\section{Robot Specifications}

Collaborative robots with high reliability can be perfect options to perform either repetitive tasks or tasks that do not need special skills. The concept of human-machine interaction has been introduced to fill the gap between the manual operations and the fully-automated operations. A proper design and conceptual plan based on the current norms and regulations will result in improving the operator safety in the shared workspace. Nowadays the robots' structure has been improved and they can recognize and react to objects during eventual occasional collisions without any unstable situation or dangerous reaction. Having high-precision sensors in each axis makes the robot manipulator very sensitive, and this contributes to increased safety and productivity. The considered robot's scheme and specifications are presented in Figure 5 and Table 9, respectively [20].

Table 9. KUKA robot characteristics (www.kuka.com) [20].

\begin{tabular}{cc}
\hline \multicolumn{2}{c}{ Range of Motion } \\
\hline A1 & $\pm 170^{\circ}$ \\
A2 & $\pm 120^{\circ}$ \\
A3 & $\pm 170^{\circ}$ \\
A4 & $\pm 120^{\circ}$ \\
A5 & $\pm 170^{\circ}$ \\
A6 & $\pm 120^{\circ}$ \\
A7 & $\pm 175^{\circ}$ \\
\hline Speed with Rated Payload \\
\hline A1 & $\pm 85^{\circ} / \mathrm{s}$ \\
A2 & $\pm 85^{\circ} / \mathrm{s}$ \\
A3 & $\pm 100^{\circ} / \mathrm{s}$ \\
A4 & $\pm 75^{\circ} / \mathrm{s}$ \\
A5 & $\pm 130^{\circ} / \mathrm{s}$ \\
A6 & $\pm 135^{\circ} / \mathrm{s}$ \\
A7 & $\pm 135^{\circ} / \mathrm{s}$ \\
\hline
\end{tabular}


LBR IIwa 14 R820 Specifications: rated payload: $14 \mathrm{~kg}$; number of axes: 7; wrist variant: in-Line wrist; mounting flange A7: DIN ISO 9409-1-A50; installation oosition: any; repeatability (ISO 9283): $\pm 0.15 \mathrm{~mm}$; axis-specific torque accuracy (of maximum torque): $\pm 2 \%$; weight: $29.5 \mathrm{~kg}$; protection rating of the robot: IP54; maximum reach: $820 \mathrm{~mm}$; sound level: $<75 \mathrm{~dB}$ A.

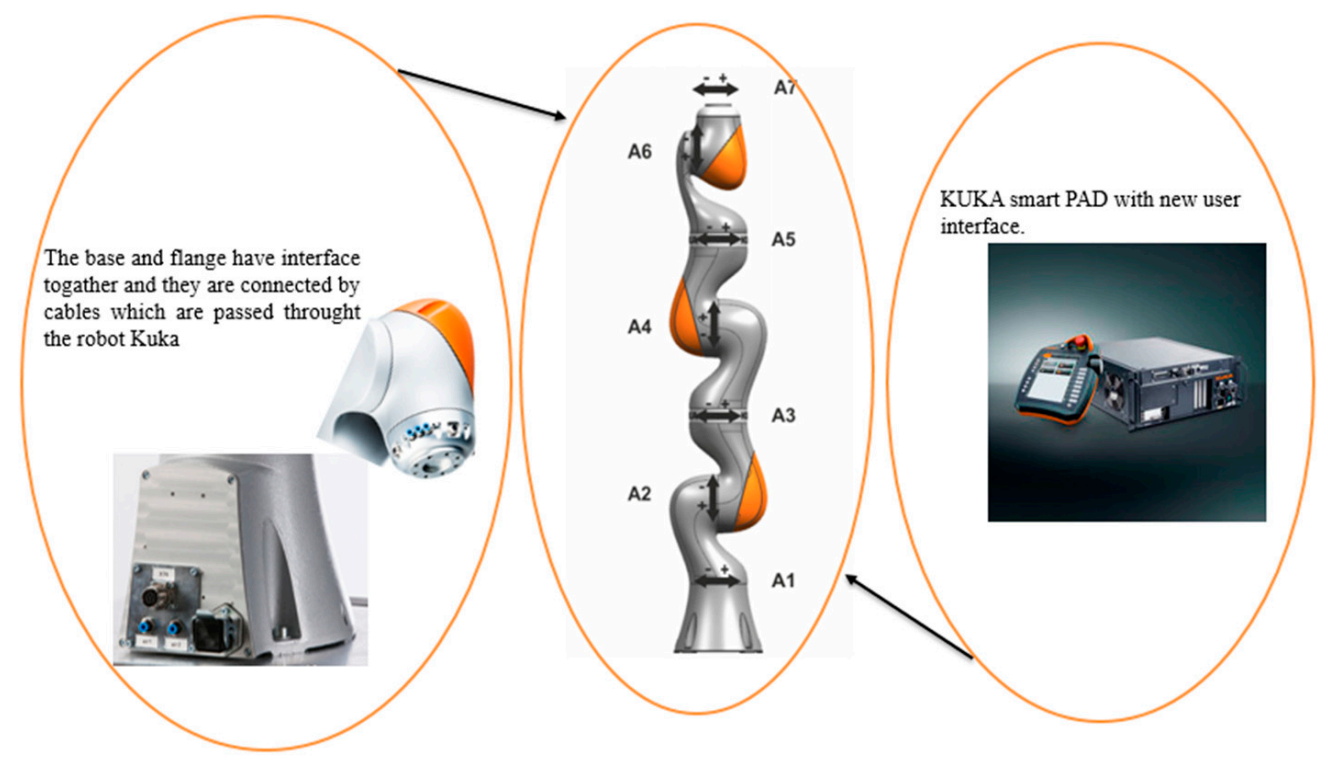

Figure 5. KUKA LBR and its controller (www.kuka.com) [20].

\section{Task Decomposition According to HTA}

There are various methods available for analysis of the operation tasks. These methodologies include the hierarchal task analysis (HTA), goal-directed task analysis, and cognitive tasks that are used to model human-robot interactions [21]. The HTA method is a scientific method used for determining human tasks, regarding different ergonomics and human factors [22]. HTA has numerous applications in different areas, such as entertainment, police and military, space exploration, manufacturing, and mining and agriculture [23]. In order to constitute the HTA diagram, all tasks should be defined as goals and sub-goals; they all must be completed to achieve the final goal [24]. In this specific study of human-robot collaboration, HTA [25-27] would be a very effective method to determine the collaborative tasks between humans and robots. The same scenario applied for AHP is used for the HTA method. To complete this activity, the same three expert personnel participated in the planning and defining of tasks; one person was responsible for managing and consulting, with more than five years of experience, and the two others were responsible for programming and running the application. The two persons trained in programming and safety regulations of robots, responsible for performing the collaborative activity, worked with the robotic prototype in the laboratory environment; one was responsible for direct collaboration and assistance with the robot and one took care of monitoring tasks and turning off the robot in the case of emergency. The robot programmer was trained for a year in the java programming exclusively used for the KUKA robot; the other expert is a $\mathrm{PhD}$ researcher who has studied the challenges and difficulties of human-robot collaborative procedures for more than three years. The overall methods flowchart for defining the human-robot collaboration task is presented in Figure 6. As is clear from Figure 6, the first step is data acquisition by direct observation in a real production environment. After recording all necessary information, the operation sequences are categorized based on the related skills and capabilities to clear the framework objective. Once the operation sequences are identified, the general process should be decomposed into separated unified tasks according to the hierarchal task analysis (HTA) method $[25,26]$. 
This methodology helps to distinguish between operator and robot roles [11] in the assembly process, as shown in Figures 7 and 8. Based on Figures 7 and 8, different roles were defined for the human and the robot; however, the main tasks for the operator include inserting screws and hubs, while the robot is tasked with performing the assembly process and tightening the screws. In the fourth step, HTA is applied to combine the operator and robot tasks in a collaborative order, which constitutes the new task table. Finally, the suggested hybrid task algorithm should be evaluated to verify the feasibility of the proposed methodology. Using the HTA method, tasks are defined as sub-goals, as shown in Table 10, with the related task's process time period. In order to constitute the HTA algorithm of the brake disc assembly, the main goal of the system is considered as equal to the main robot manipulator's goal; in this way, the assembly of the brake disc is recorded as the super-ordinate goal 0 in the HTA algorithm, as shown in Table 10. To achieve the main goal, sub-goals should be completed. Sub-goals are subdivided into three groups: sub-goal 1 (assembles the dust protection plate); sub-goal 2 (positions the hub on the plate and change the tip for screwing); and sub-goal 3 (completing the assembly of brake disc). Sub-goals are subsequently divided into minor goals, as shown in Table 10. It is important to mention that when there is a need for more details, it is necessary to add lower-level goals to the model.

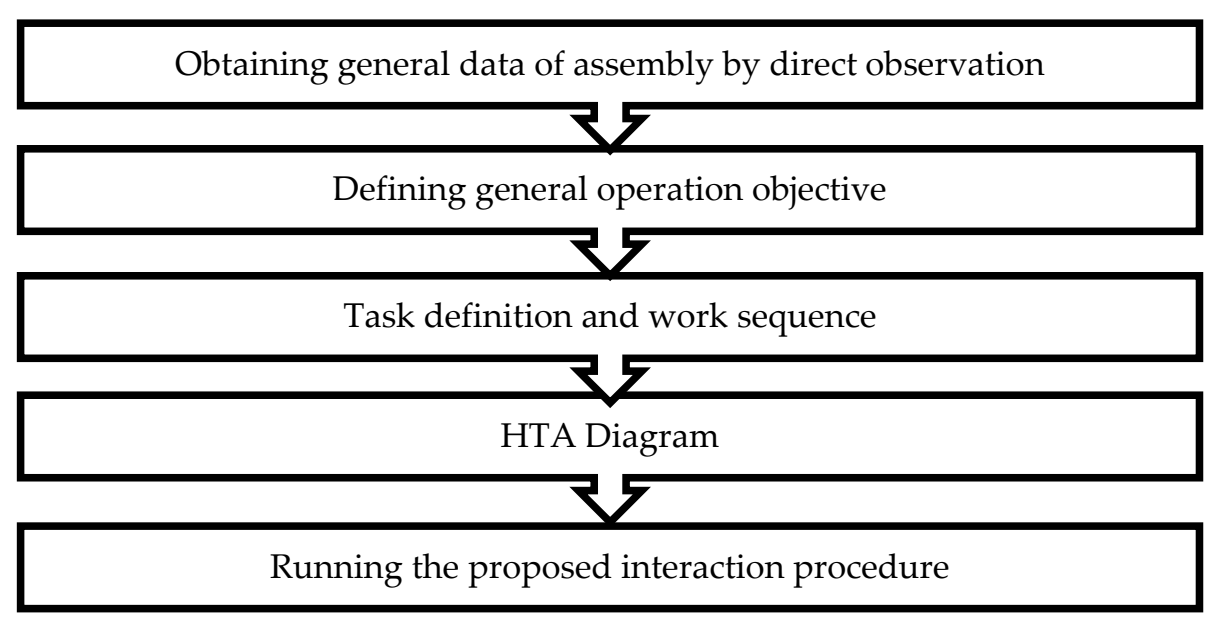

Figure 6. Task development sequence. 


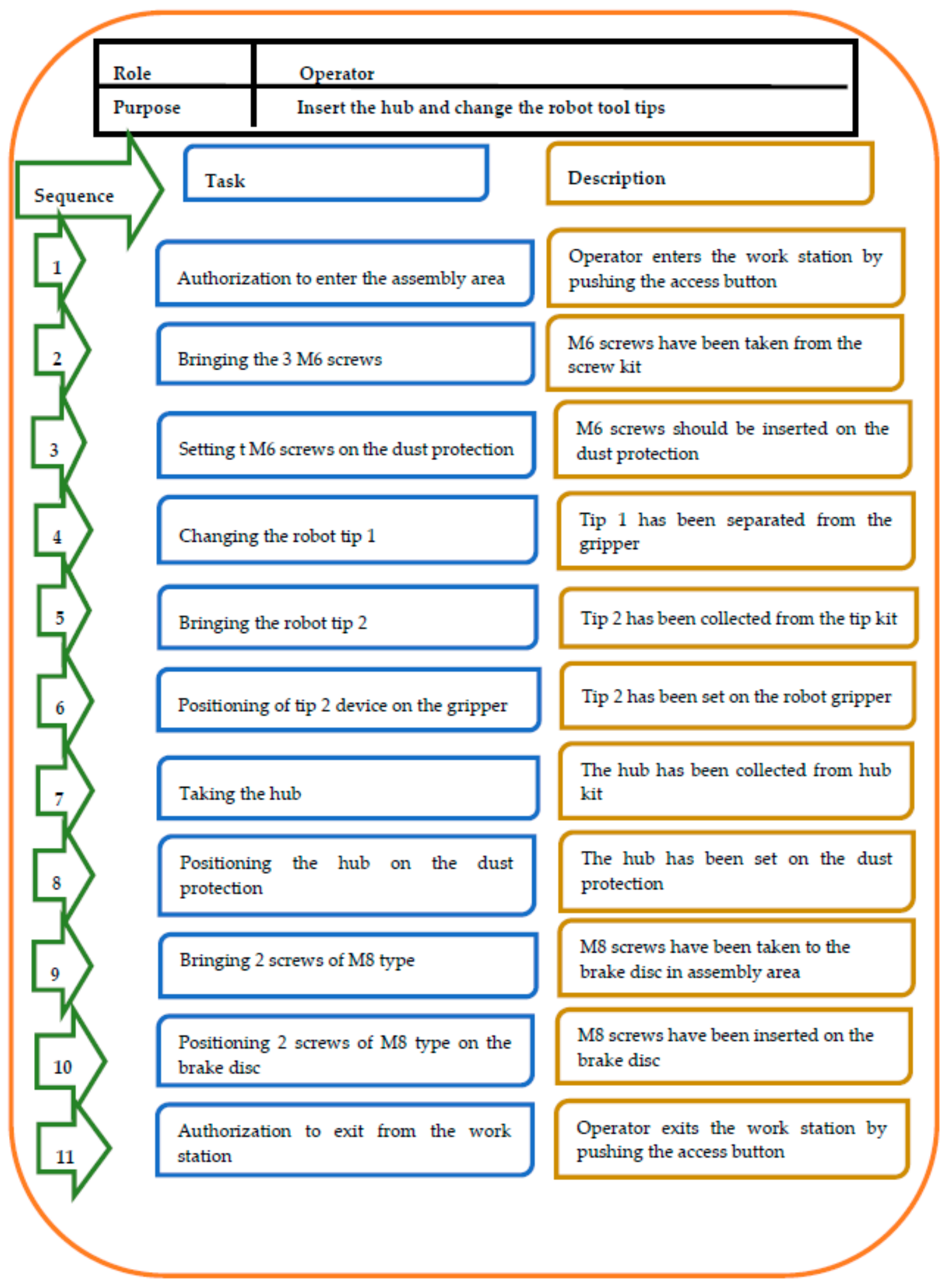

Figure 7. Operator's tasks allocation and sequences. 


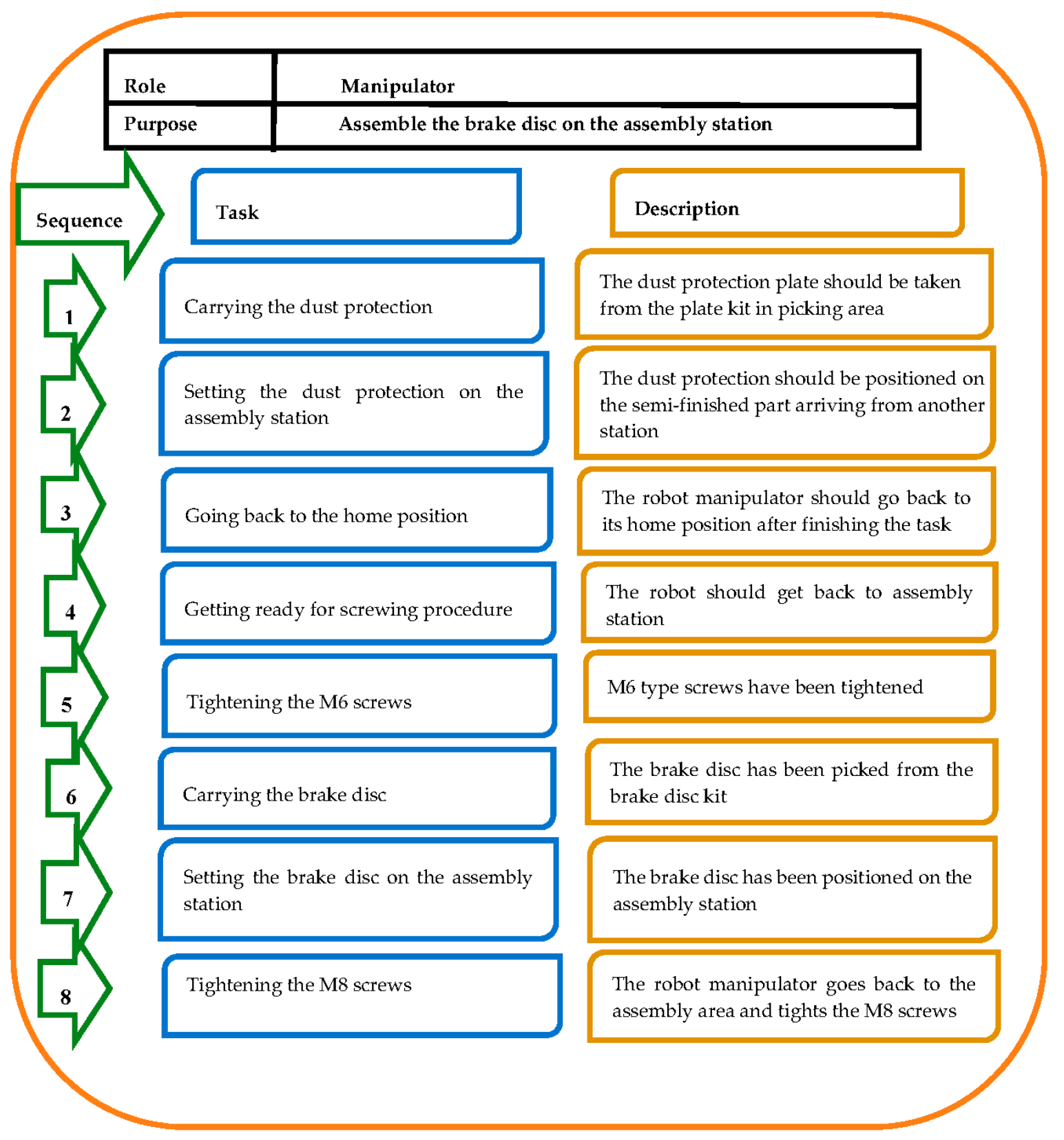

Figure 8. Robot manipulator's tasks allocation and sequences. 
Table 10. Hierarchical task analysis (HTA) table of the brake disc assembly operation.

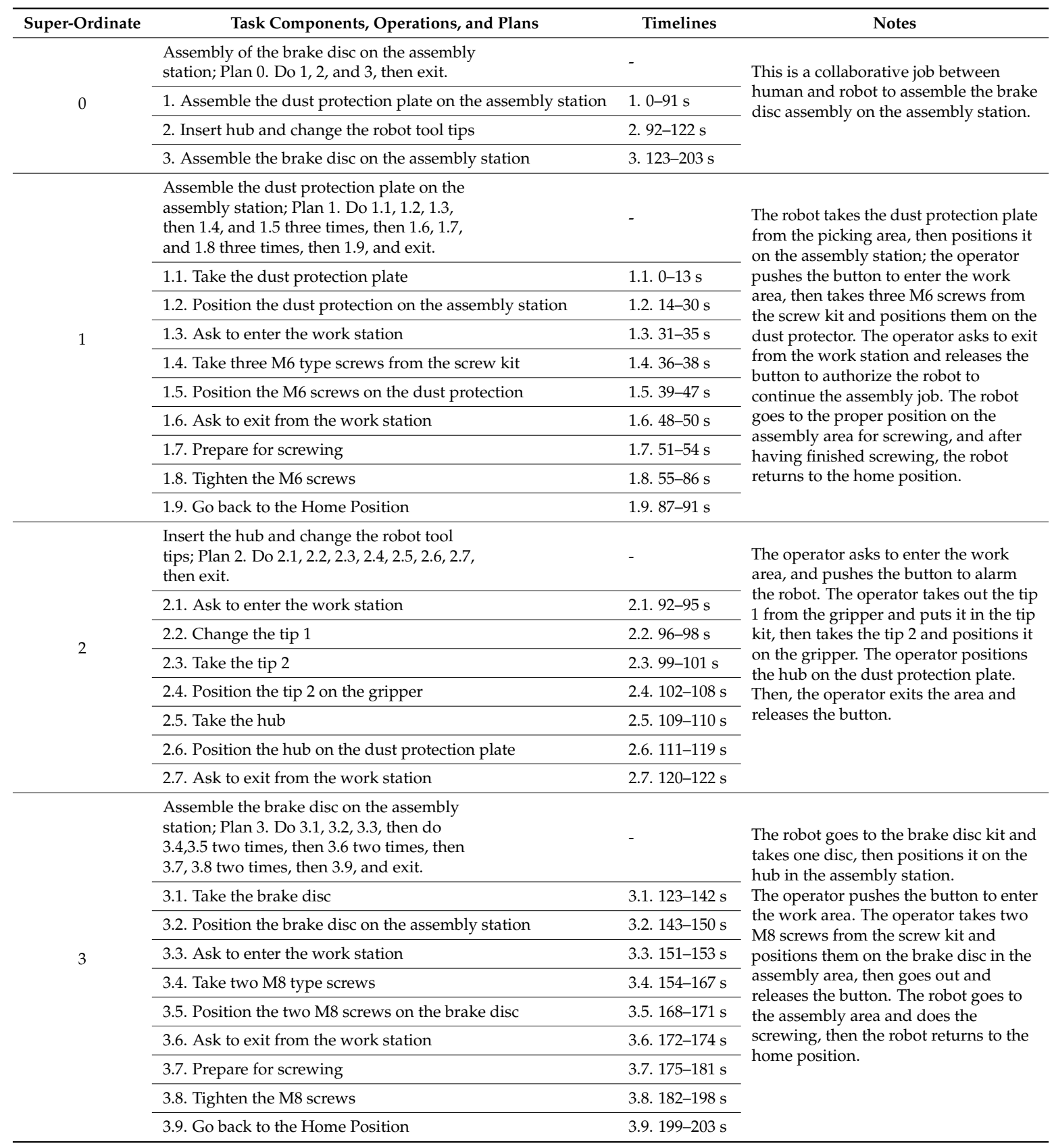

\section{Simulation Procedure}

Virtual environments have vital roles in current manufacturing industries, as they facilitate the design of different manufacturing production lines and provide visual analysis tools to create the manufacturing process. Using a virtual environment reduces the risk connected to production changes, production planning time, and cost, while improving the process ergonomic safety [28,29]. There are various software programs available for simulating manufacturing production lines, and one of the most common is Siemens Tecnomatix software (version 11.1,80, Siemens, Munich, BY, Germany, 2012). Tecnomatix is developed by the Siemens Company and is practically subdivided into different packages designed to accomplish particular tasks. The package used for analyzing the ergonomic effects on humans is called JACK software (version 11.1,80, Siemens, Munich, BY, Germany, 2012); the package used for creating digital models of production lines and examining different possibilities 
for system layouts is called Plant Simulation; and the package in which the feasibility of the product assembly process is analyzed is called Process Simulate, used for offline programming of robots and the manufacturing process. In order to simulate the process of the brake disc assembly, the Tecnomatix Process Simulate package was used.

\subsection{Computer-Aided Design}

All the parts are prepared in NX (version 11.1,80, Siemens, Munich, BY, Germany, 2012) and CATIA (v5.20. Dassault System, Vélizy-Villacoublay, France, 2009); however, if any part is designed out of the NX software it is necessary to transfer all the file formats to the JT (Jupiter Tesselation) format in NX. The parts imported to the NX software are divided into two categories; the first category is related to the static links, for which no movements are defined in the virtual environment. In other words, they are stationary parts of the assembly line, such as fixtures, bases, rails, desk, upright, bearing, screws, and snap rings, as shown in Figure 9. On the other hand, the parts in which movement is considered are called dynamic links, such as platforms, grippers, robots, etc. In order to input all the designed parts into the Process Simulate software to build the assembly line, the only readable format for the files are in the COJT format; thus, the file formats are converted in Process Simulate software once again to the COJT format.
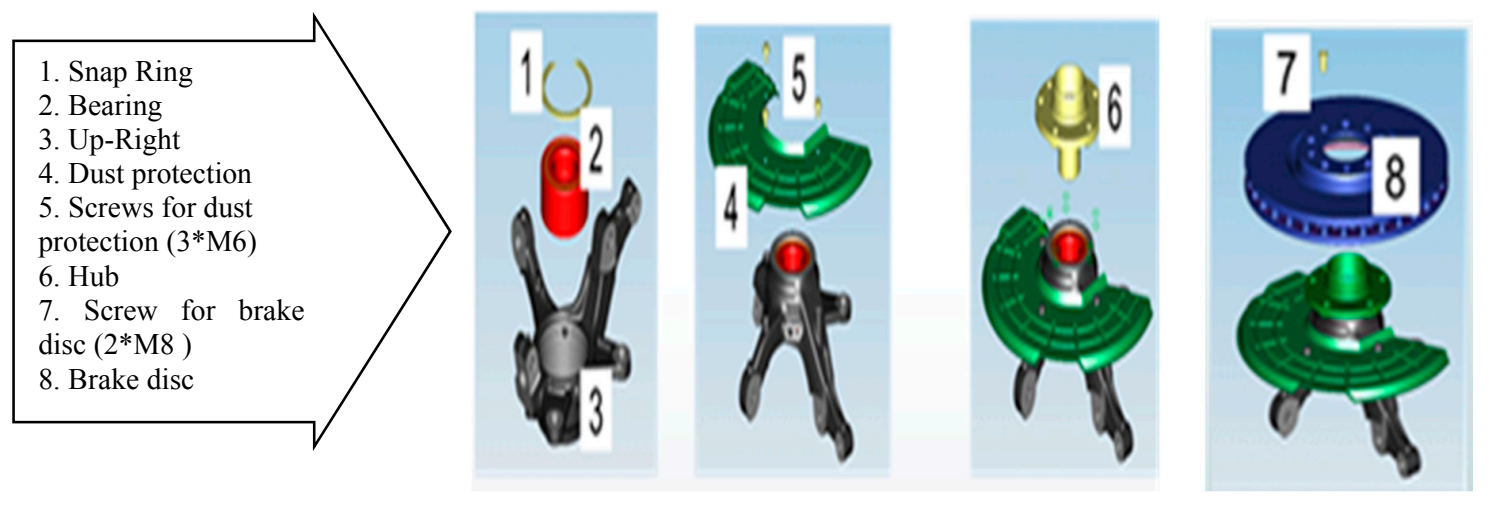

Figure 9. CAD part in NX software.

\subsection{Gripper}

Generally, robots consist of arms and an end effector; the gripper is one of the most common type of end effectors mounted on the end of the robot arm. The primary role of the gripper is for the picking and placing of various objects during the process; however, it is possible that the gripper has multifunctional tasks, as in this research, in which the tasks include picking, placing, and screwing. Based on the operational tasks of the gripper, it has three parts: the base part, the screwing part, and the fingers, as shown in Figure 10. As mentioned before, all the assembly line parts should be prepared in the format required by the NX software and then imported into Process Simulate, including the gripper parts. In order to simplify the kinematic representation of the gripper in Process Simulate [29], static and dynamic links should be defined, as shown in Figure 8. The model of the gripper components is subdivided into seven parts, including one link that belongs to the base part which has static link characteristics, five links that belong to the finger part and have dynamic link characteristics, and one link that belongs to the screw part and has dynamic link characteristics. After the gripper is imported into Process Simulate, the kinematic characteristics are used for defining the dynamic link and motion of the gripper.

There are two types of simulation available in Tecnomatix Process Simulate software: time-based simulation and event-based simulation. Usually, time-based simulation includes resources, products, and operations, while for event-based simulation signals should be defined. Time-based simulation is implemented during a specific period of time in which the sequence of operations is predefined. 
In order to constitute a manufacturing process using the time-based method, it is necessary to define kinematic motions for the non-stationary parts. The main difference between these two types of simulation is that event-based simulations do not have a specific time process, and the sequence of operations is defined according to the process logic box; this means that this simulation uses signal-based logic to determine the operations sequence [30]. In this research, a time-based approach-due to the application of a safety button instead of a safety eye, which requires sensors in simulation - was used to model the manufacturing process. A sample of a time-based simulation in Tecnomatix Process Simulate is shown in Figure 11. In Figure 11, in a time-based representation, the operation times needed for accomplishing tasks by the operator and robot in each step are shown. The total time resulting from the procedure simulation is $120 \mathrm{~s}$. Figure 12 shows the collaborative environment between the human and robot, as well as the completed brake disc assembly.

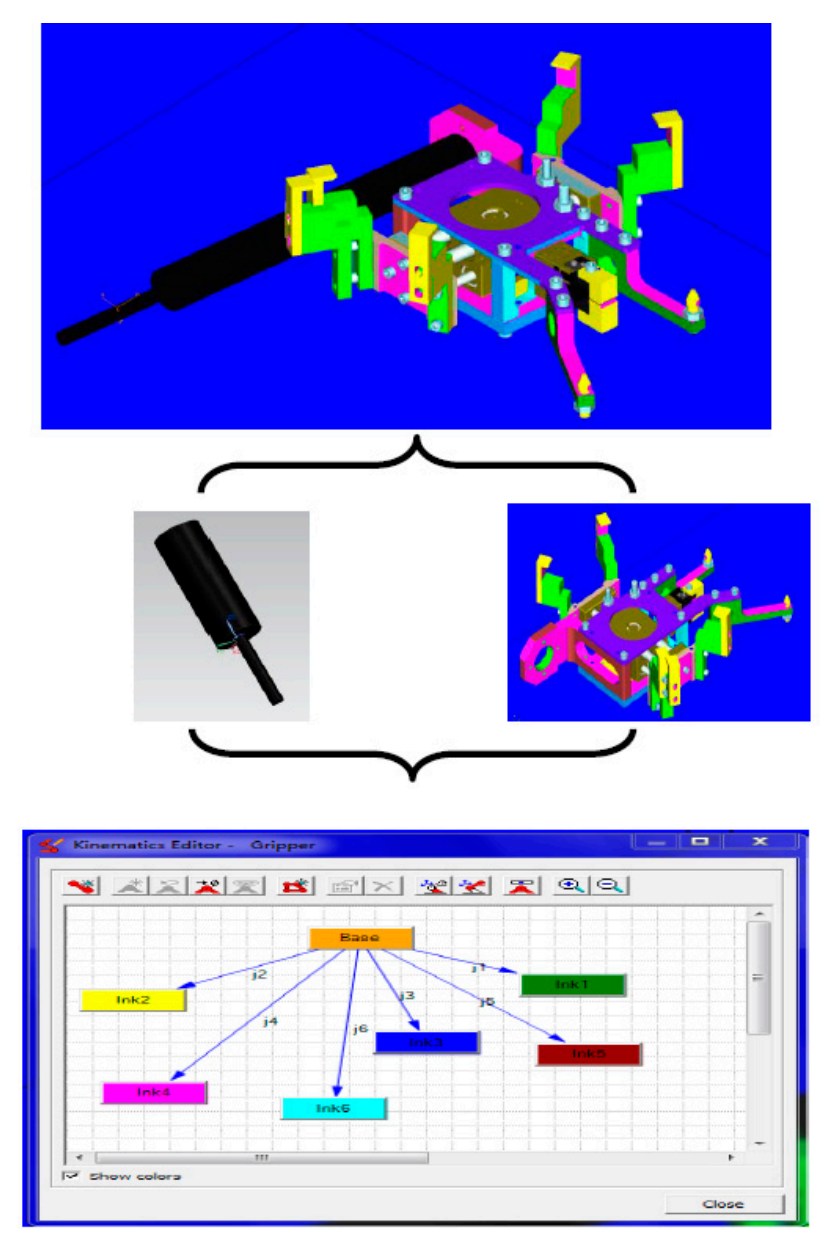

Figure 10. CAD model and kinematic characteristics of the gripper. 


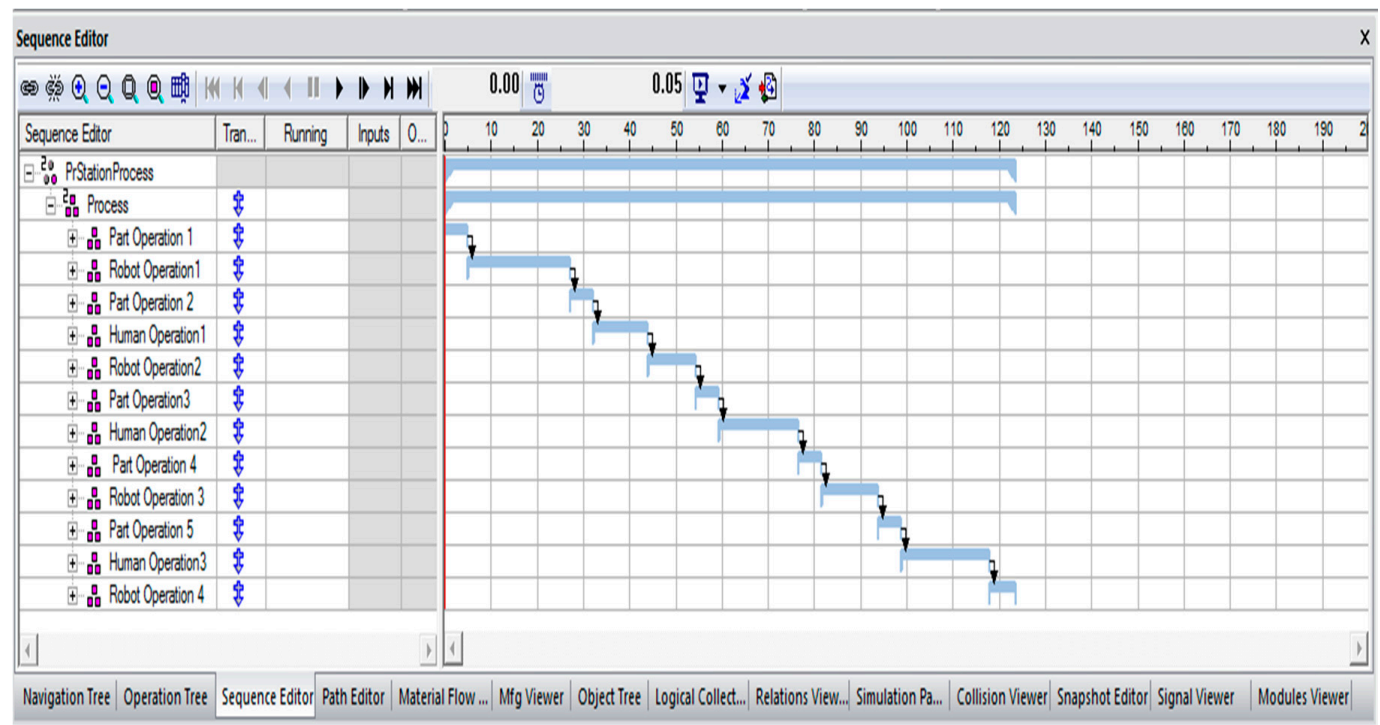

Figure 11. Gantt chart of operations in the time-based mode.

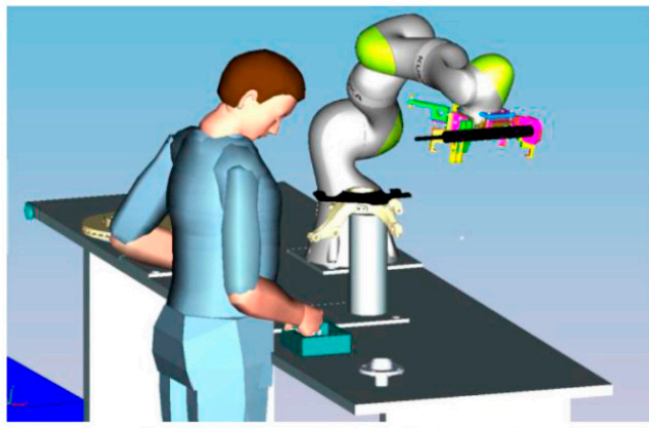

(a) Collaborative environment

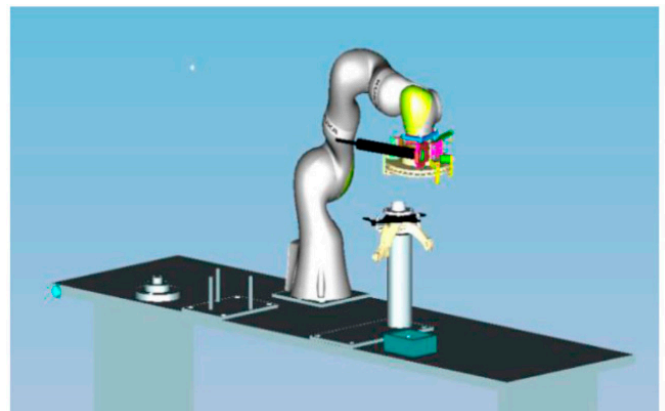

(b) Brake disc assembly by robot

Figure 12. (a) Collaborative environment, and (b) brake disc assembly by the robot.

\section{Evaluation and Discussion}

Copying the manual assembly process of the brake disc, the primary operation sequence of the automated process was defined, as shown in Figure 13. As mentioned before, since each operator approximately assembles 160 brake discs in each day shift, it is obvious that they will undergo a very large workload (around $800 \mathrm{~kg}$ ); this workload may cause serious ergonomic injuries, such as muscular pain for the operator, over a long period of time.

The use of the HTA method provides the possibility of combining human and robot tasks in a collaborative order, as shown in Figure 14. As mentioned before, three personnel were involved in this activity; one person for managing and consulting and the other two trained for the programming and running of the application. Tests were repeated five times during two weeks of working with the robotic prototype in laboratory conditions to gain a statistical basis.

As discussed previously, the main responsibilities of the assistant robot are picking and placing of the dust protection plate and the brake disc. In order to evaluate the feasibility of the hybrid assembly process proposed by the HTA method, few tasks were considered and the assembly process was modeled in a virtual environment. The total assembly process time based on the initial HTA diagram is $203 \mathrm{~s}$. The HTA method facilitated the definition of tasks for operator and robot in a collaborative manner; however, some defects were observed during testing. It was observed that, when the operator intends to put the M8 screws on the brake disc in the last phase of assembly, the robot manipulator is partially obstructing the operator's sight. This occurrence forced the operator to change his position 
regularly to complete the task properly. Two solutions have been proposed to solve this problem; the first one is to return the robot manipulator to its home position, and the second one involves the use of the impedance control of the robot and hand-guided method (HG).

Although it seems that the first solution would be a perfect one, it is quite costly. Imagine that each time the robot manipulator has to come back to its home position and again return to the previous position for the screwing and tightening operation; this will be very time-consuming and thus reduce productivity. However, based on the second method, the hand-guided method, the robot is allowed to move only in predefined directions determined by the operator.

The robot was moved by the operator to the non-disturbing position and the operator put the screws on the brake disc. Regarding to abovementioned description and the hand-guided method as an extra task, the final collaborative tasks were redefined and the modified task sequences are presented in Figure 15. The schematic of collaborative work environment in laboratory is shown in Figure 16. It is worth mentioning that adding the hand-guided method increased the total processing time to $210 \mathrm{~s}$.

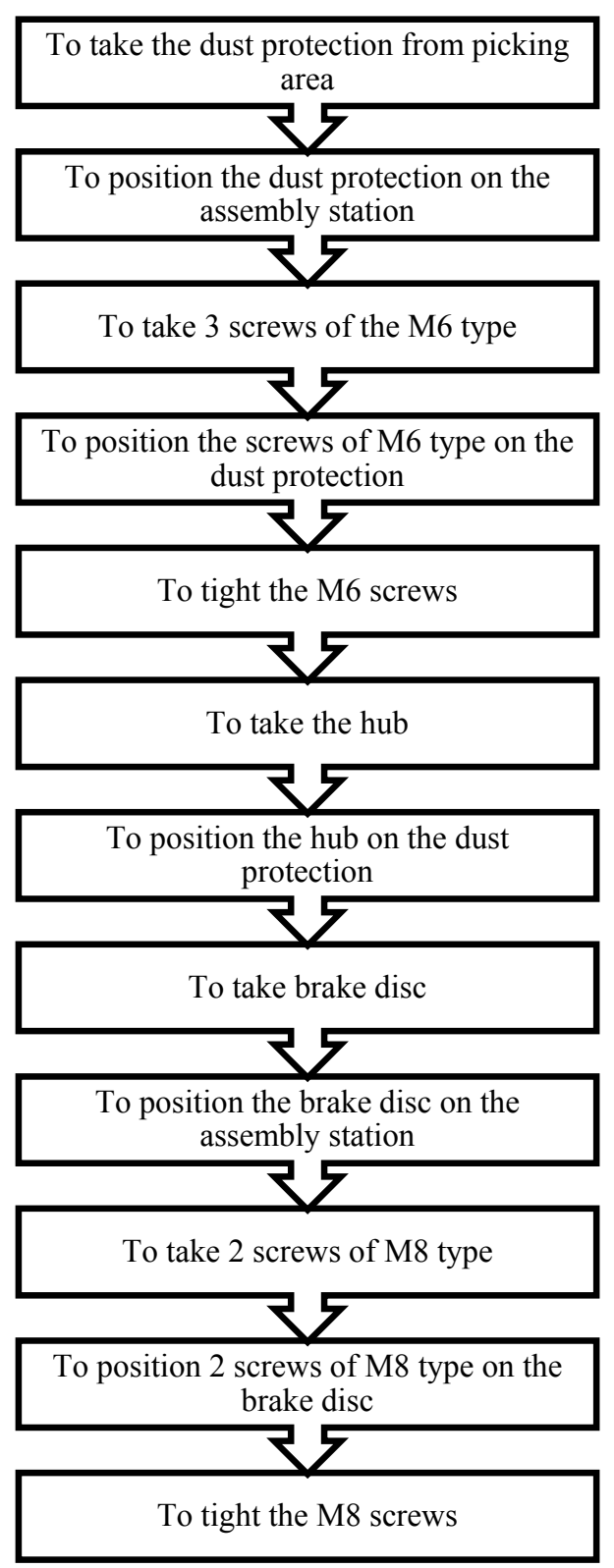

Figure 13. The initial assembly operation sequence. 
To take the dust protection from picking area [Robot]

\section{Y}
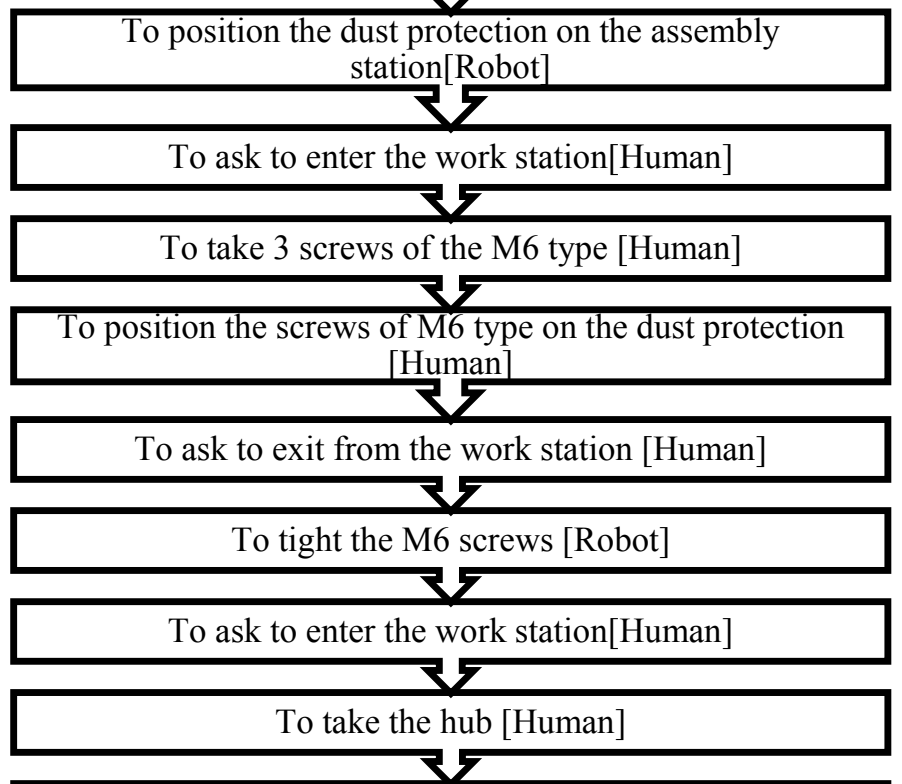

To position the hub on the dust protection [Human]

To ask to exit from the work station [Human]

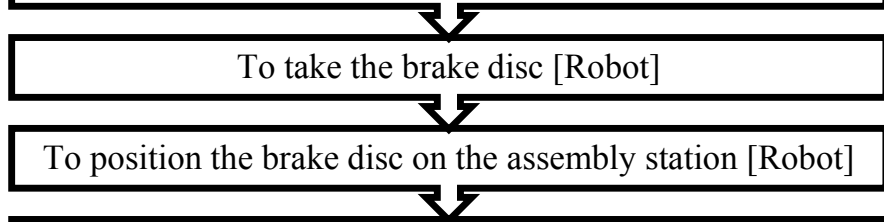

To ask to enter to the work station [Human]

To take 2 screws of M8 type [Human]

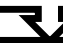

To position 2 screws of M8 type on the brake disc[Human]

To

To ask to exit from the work station [Human]

To tight the M8 screws [Human]

Figure 14. Modified assembly operation sequence with a robot. 


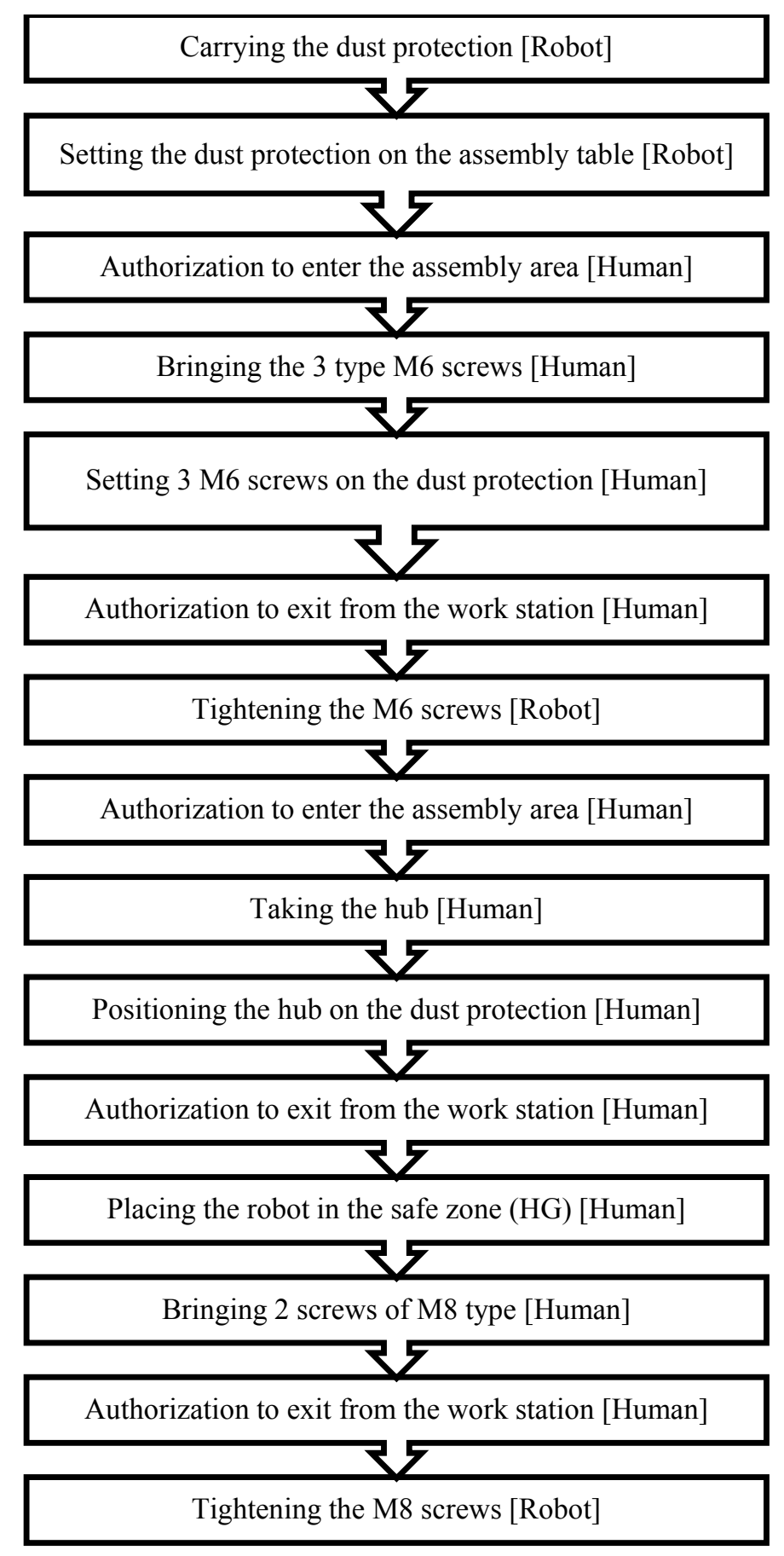

Figure 15. Human-robot collaborative task allocation with HTA. 


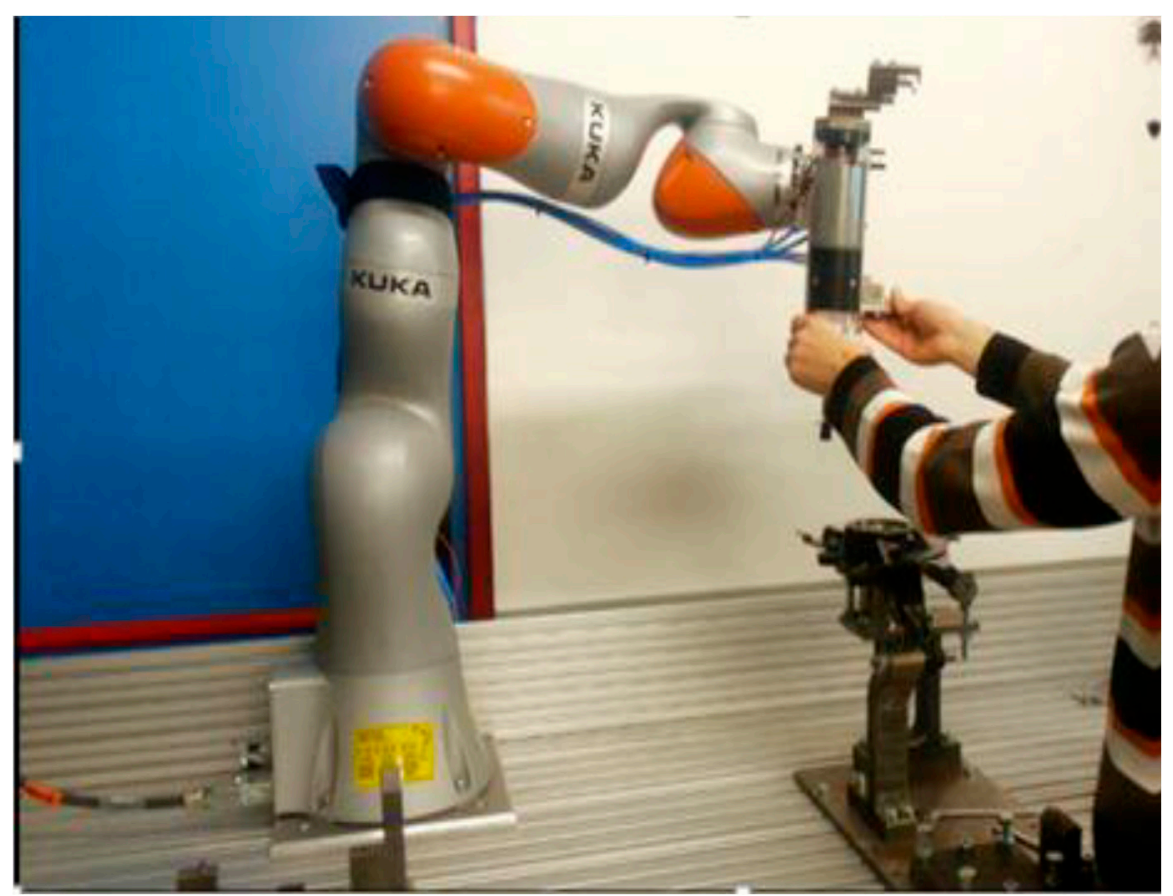

Figure 16. Human-robot collaboration with the hand-guided (HG) method during the assembly process of a brake disc.

\section{Conclusions}

In this research, the feasibility of human-robot collaboration was investigated for a case study (assembly of a brake disc) in experimental and simulation scenarios. In the first step, the AHP method was applied to prove the general advantage of the human-robot collaboration over the manual assembly solution. Productivity, quality, human fatigue, and safety were considered as the base criteria for the comparison of the possible different solutions while applying the AHP method. Using the HTA method, the primary algorithm for allocating the collaborative tasks to humans and robots was constituted. In the third step, the assembly process was simulated using the Tecnomatix Process Simulate virtual environment software to test the effectiveness of the HTA method in the case of task allocation. In order to obtain realistic results, the gripper that had been designed for the particular considered application was fully modeled. Finally, the feasibility of the design was tested using the laboratory environment and defects were recorded. It was observed that, during the assembly, the robot manipulator obstructed the operator's sight, preventing them from completing the assembly properly. The hand-guided method was used to solve this problem based on the available standards in human-robot collaboration. According to the manual assembly process, every day each operator should work $8 \mathrm{~h}$ in one shift, each brake disc weighs around $5 \mathrm{~kg}$, and the assembly of one brake disc takes around $3 \mathrm{~min}$. Considering the operator work shift hours and the brake disc assembly period, the operator should assemble approximately 160 brake discs and lift $800 \mathrm{~kg}$ throughout each working day. Considering at least 200 working days in a year, he should lift around 160,000 kg; in other words, he will undergo to a load of $1600 \mathrm{kN}$. This workload in a year could affect the operator fatigue accumulation, tiredness, and may cause serious injuries to the operator's muscles. This situation can also influence productivity and quality, because sometimes the operator is tired or has some pain in his muscles; this can cause the inappropriate insertion of the brake disc on the dust protection plate or the insufficient tightening of screws. These will cause a faulty assembly and decrease the quality and productivity. Although the collaborative procedure increases the total assembly time (210 s) in comparison with the manual procedure (180 s), operator ergonomics are improved and the risk of injury is considerably reduced. 
Acknowledgments: This work was supported by the Politicenico di Torino for research and Development of university projects.

Author Contributions: All authors contributed substantially to the reported work. Sahar Heydaryan, Joel Suaza Bedolla and Giovanni Belingardi were the originator of the idea of this study and prepared the manuscript. Sahar Heydaryan designed the experimental technique and performed the simulations. Sahar Heydaryan, Joel Suaza Bedolla and Giovanni Belingardi wrote the paper.

Conflicts of Interest: The authors declare no conflict of interest.

\section{References}

1. Rahimi, M.; Karwowski, W. Human-Robot Interaction; Taylor \& Francis: London, UK, 1992; pp. 4-5, ISBN 0-203-21093-X.

2. Unhelkar, V.V.; Siu, H.C.; Shah, J.A. Comparative performance of human and mobile robotic assistants in collaborative fetch-and-deliver tasks. In Proceedings of the 2014 ACM/IEEE International Conference on Human-Robot Interaction (HRI '14), Bielefeld, Germany, 3-6 March 2014; pp. 82-89.

3. Tan, J.T.C.; Duan, F.; Zhang, Y.; Kato, R.; Arai, T. Safety design and development of human-robot collaboration in cellular manufacturing. In Proceedings of the IEEE International Conference on Automation Science and Engineering, Bangalore, India, 22-25 August 2009; pp. 537-542.

4. Cherubini, A.; Passama, R.; Crosnier, A.; Lasnier, A.; Fraisse, P. Collaborative manufacturing with physical human-robot interaction. Robot. Comput. Integr. Manuf. 2016, 40, 1-13. [CrossRef]

5. Barbosa, G.; Carvalho, J. A proper framework for design of aircraft production system based on lean manufacturing principles focusing to automated processes. Int. J. Adv. Manuf. Technol. 2014, 72, 1257-1273. [CrossRef]

6. Belingardi, G.; Heydaryan, S.; Chiabert, P. Application of speed and separation monitoring method in human-robot collaboration: Industrial case study. In Proceedings of the XVII International Scientific Conference on Industrial Systems (IS'17), Novi Sad, Serbia, 4-6 October 2017.

7. Di Gironimo, G.; Patalano, S.; Tarallo, A. Innovative assembly process for modular train and feasibility analysis in virtual environment. Int. J. Interact. Des. Manuf. 2009, 3, 93-101. [CrossRef]

8. Andrisano, A.O.; Leali, F.; Pellicciari, M.; Pini, F.; Vergnano, A. Hybrid Reconfigurable System design and optimization through virtual prototyping and digital manufacturing tools. Int. J. Interact. Des. Manuf. 2012, 6, 17-27. [CrossRef]

9. Matsas, E.; Vosniakos, G.-C. Design of a virtual reality training system for human-robot collaboration in manufacturing tasks. Int. J. Interact. Des. Manuf. 2017, 11, 139-153. [CrossRef]

10. Pellicciari, M.; Leali, F.; Andrisano, A.O.; Pini, F. Enhancing changeability of automotive Hybrid Reconfigurable Systems in digital environments. Int. J. Interact. Des. Manuf. 2012, 6, 251-263. [CrossRef]

11. Tan, J.T.C.; Duan, F.; Zhang, Y.; Watanabe, K.; Pongthanya, N.; Sugi, M.; Yokoi, H.; Arai, T. Assembly information system for operational support in cell production. Manuf. Syst. Technol. New Front. 2008, 209-212. [CrossRef]

12. Saaty, T.L. Decision making with the analytic hierarchy process. Int. J. Serv. Sci. 2008, 1, 83-98. [CrossRef]

13. Saaty, T.L. How to make a decision: The analytic hierarchy process. Interfaces 1994, 24, 19-43. [CrossRef]

14. Saaty, T.L.; Vargas, L.G. Models, Methods, Concepts \& Applications of the Analytic Hierarchy Process, 2nd ed.; Springer: New York, NY, USA, 2012; pp. 1-69, ISBN 978-1-4614-3596-9.

15. Saaty, T.L. How to make a decision: The analytic hierarchy process. Eur. J. Oper. Res. 1990, 48, 9-26. [CrossRef]

16. Saaty, T.L.; Kearns, K.P. Analytical Planning: The Organization of System, 1st ed.; Elsevier: Amsterdam, The Netherlands, 2014; Volume 7, pp. 25-47.

17. Harker, P.T.; Vargas, L.G. The theory of ratio scale estimation: Saaty's analytic hierarchy process. Manag. Sci. 1987, 33, 1383-1403. [CrossRef]

18. Al-Harbi, K.M. Application of the AHP in project management. Int. J. Proj. Manag. 2001, 19, 19-27. [CrossRef]

19. International Organization for Standard. Robots and Robotic Devices-Safety Requirements for Industrial Robots-Part 2: Robot Systems and Integration; International Organization for Standard: Geneva, Switzerland, 2011.

20. KUKA. Available online: https:/ / www.kuka.com/ (accessed on 15 February 2016). 
21. Adams, J.A. Human-robot interaction design: Understanding user needs and requirements. In Proceedings of the Human Factors and Ergonomics Society Annual Meeting, Orlando, FL, USA, 26-30 September 2005; SAGE Publications: Los Angeles, CA, USA, 2005; pp. 447-451.

22. Hodgkinson, G.P.; Crawshaw, C. Hierarchical task analysis for ergonomics research: An application of the method to the design and evaluation of sound mixing consoles. Appl. Ergon. 1985, 16, 289-299. [CrossRef]

23. Annett, J. Hierarchical Task Analysis. In Handbook of Cognitive Task Design; Hollnagel, E., Ed.; Lawrence Erlbaum Associates: Mahwah, NJ, USA; London, UK, 2003; Chapter 2; pp. 17-33, ISBN 1-4106-0777-1.

24. Annett, J.; Duncan, K.D. Task Analysis and Training Design; John Wiley \& Sons: New York, NY, USA, 1967.

25. Kirwan, B.; Ainsworth, L.K. A Guide to Task Analysis: The Task Analysis Working Group; Taylor \& Francis: London, UK, 1992; pp. 35-217, ISBN 0-7484-0057-5.

26. Shepherd, A. HTA as a framework for task analysis. Ergonomics 1998, 41, 1537-1552. [CrossRef] [PubMed]

27. Stanton, N.A. Hierarchical task analysis: Developments, applications, and extensions. Appl. Ergon. 2006, 37, 55-79. [CrossRef] [PubMed]

28. Guerrero, L.V.; López, V.V.; Mejía, J.E. Virtual Commissioning with Process Simulation (Tecnomatix). Comput. Aided Des. Appl. 2014, 11, 11-19. [CrossRef]

29. Chan, D.S. Simulation modelling in virtual manufacturing analysis for integrated product and process design. Assem. Autom. 2003, 23, 69-74. [CrossRef]

30. Popovič, R.; Kliment, M.; Trebuňa, P.; Pekarčíková, M. Simulation as a tool for process optimization of logistic systems. Acta Logist. 2015, 2, 1-5.

(C) 2018 by the authors. Licensee MDPI, Basel, Switzerland. This article is an open access article distributed under the terms and conditions of the Creative Commons Attribution (CC BY) license (http:/ / creativecommons.org/licenses/by/4.0/). 